\title{
Corticosteroids in liver disease: Studies on the biological conversion of prednisone to prednisolone and plasma protein binding
}

\author{
L. W. POWELl AND ELIZABETH AXELSEN
}

From the Department of Medicine, University of Queensland, Royal Brisbane Hospital, Brisbane, Australia

SUMMARY The conversion of prednisone to the biologically active corticosteroid prednisolone and the degree of plasma protein binding of prednisolone were studied in 22 patients with acute or chronic liver disease and in eight control subjects. In patients whose disease was active at the time of study, as judged by elevated serum levels of bilirubin and transaminase, significantly higher levels of plasma prednisolone were obtained after prednisolone administration than after equivalent doses of prednisone. In addition, the amount of unbound drug in the plasma was higher in patients with active disease. There was a significant correlation between the extent of plasma protein binding of prednisolone and the serum albumin concentration. Azathioprine did not affect the plasma binding of prednisolone in vitro. The plasma half-life of prednisolone was prolonged in two of three patients with chronic liver disease studied.

These results suggest that in patients with acute hepatitis or active chronic liver disease there is impairment of reduction of the 11-oxo group of prednisone, and also impaired ring $A$ reduction of prednisolone. Thus, incomplete conversion of prednisone to prednisolone occurs, which is a necessary step for biological activity; on the other hand there is also impairment of prednisolone degradation. These, together with low serum albumin concentrations which are associated with higher levels of circulating unbound prednisolone, result in quite different levels of biologically active corticosteroids compared with equivalent doses of prednisone or prednisolone in subjects without liver disease. The findings have important practical implications for the use of corticosteroids in patients with active liver disease.

Corticosteroids have been used for over 20 years in the treatment of patients with liver disease, and recent controlled clinical studies have provided strong evidence of a significant therapeutic effect of prednisolone in active chronic hepatitis (Mackay, 1968; Copenhagen study group for liver disease, 1969; Cook, Mulligan, and Sherlock, 1971). However, little is known about the metabolism or plasma protein binding of prednisolone in patients with liver disease. Drug régimes and dosages vary widely and are chosen arbitrarily, often on the assumption that the biological half-life of the steroids is normal. It is widely assumed, although unproven, that prednisone is consistently converted to the biologically active prednisolone even by the diseased liver, and that these compounds are therefore equally effective therapeutically (Jenkins and Sampson, 1967). Received for publication 27 June 1972.
Furthermore, the extent to which plasma protein binding of prednisolone is affected by the concurrent administration of other drugs such as azathioprine is unknown.

This paper reports the results of studies of the extent to which hepatic disease affects the biological conversion of prednisone to prednisolone, the degree of plasma protein binding of prednisolone in these patients, and the effects of azathioprine on plasma protein binding of prednisolone.

\section{Methods and Patients Studied}

Of the eight control subjects, three were informed healthy volunteers (medical graduates) and five were hospital inpatients without clinical or biochemical evidence of liver disease, for whom corticosteroid preparations had been prescribed for clinically 


\begin{tabular}{|c|c|c|c|c|c|c|c|c|c|c|c|}
\hline Patient & Age & Sex & Diagnosis & $S G O T^{1}$ & $S A P^{2}$ & $\begin{array}{l}\text { Serum Total } \\
\text { Bilirubin } \\
(\mathrm{mg} / 100 \mathrm{ml})\end{array}$ & $\begin{array}{l}\text { Serum Total } \\
\text { Protein } \\
(\mathrm{g} / 100 \mathrm{ml})\end{array}$ & $\begin{array}{l}\text { Serum } \\
\text { Albumin } \\
(\mathrm{g} / 100 \mathrm{ml})\end{array}$ & $B U N^{8}$ & $\begin{array}{l}\text { Peak } \\
\text { Prednisolone } \\
\text { Level }\end{array}$ & $\begin{array}{l}\text { Percentage } \\
\text { Bound } \\
\text { Prednisolone }\end{array}$ \\
\hline \multicolumn{4}{|c|}{ Controls (mean values $\pm 1 \mathrm{SE}$ ) } & $45 \pm 3 \cdot 2$ & $56 \pm 3.6$ & $0.4 \pm 0.03$ & $6.9 \pm 0.2$ & $3.7 \pm 0.1$ & $19 \cdot 2 \pm 1 \cdot 0$ & $24 \cdot 1 \pm 1 \cdot 19$ & $53.5 \pm 1.85$ \\
\hline \multicolumn{12}{|c|}{ Active' chronic hepatocellular disease (group 1) } \\
\hline 'T.A. & 32 & $\mathbf{F}$ & $\mathbf{A C H}^{\bullet}$ & 500 & 170 & 3.0 & 6.4 & $3 \cdot 1$ & 22 & $38 \cdot 5$ & $42 \cdot 5$ \\
\hline W.M. & 15 & $\mathbf{M}$ & $\mathbf{A C H}$ & 155 & 185 & 1.6 & $6 \cdot 4$ & 3.5 & 25 & $24 \cdot 0$ & $46 \cdot 0$ \\
\hline K.B. & 15 & $\mathbf{F}$ & $\mathbf{A C H}$ & 1000 & 270 & $2 \cdot 0$ & $9 \cdot 1$ & 3.0 & 10 & $28 \cdot 4$ & $48 \cdot 5$ \\
\hline \multirow[t]{3}{*}{ B.T. } & 33 & $\mathbf{F}$ & $\mathbf{A C H}$ & 1350 & 96 & $4 \cdot 1$ & $6 \cdot 3$ & $2 \cdot 8$ & 15 & 56.0 & $40 \cdot 2$ \\
\hline & & & & 60 & 40 & 0.4 & $8 \cdot 0$ & $3 \cdot 6$ & 19 & $41 \cdot 8$ & $43 \cdot 7$ \\
\hline & & & & 45 & 40 & 0.6 & $8 \cdot 5$ & $4 \cdot 3$ & 16 & $42 \cdot 6$ & 52.4 \\
\hline K.W. & 47 & $\mathbf{M}$ & $\mathbf{A C H}$ & 150 & 95 & 1.4 & $7 \cdot 2$ & 3.8 & 16 & $27 \cdot 7$ & 51.8 \\
\hline M.G. & 48 & $\mathbf{F}$ & $\mathbf{A C H}$ & 100 & 70 & $4 \cdot 7$ & $6 \cdot \overline{7}$ & $3 \cdot 3$ & 9 & 26.4 & 40.6 \\
\hline M.B. & 22 & $\mathbf{M}$ & $\mathrm{ACH}$ & 1800 & 125 & $3 \cdot 2$ & $8 \cdot 2$ & 3.0 & 10 & $24 \cdot 2$ & $46 \cdot 4$ \\
\hline A.Q. & 56 & $\mathbf{F}$ & $\mathbf{H C}^{\mathrm{s}}$ & 95 & 200 & 1.4 & $5 \cdot 6$ & $2 \cdot 5$ & 14 & $28 \cdot 0$ & 43.5 \\
\hline V.P. & 50 & $\mathbf{M}$ & $\mathbf{A C}^{6}$ & 240 & 140 & $2 \cdot 3$ & $8 \cdot 4$ & 3.6 & 22 & $31 \cdot 0$ & 60.5 \\
\hline \multicolumn{4}{|c|}{ Mean values $\pm 1 \mathrm{SE}$} & $499 \cdot 5 \pm 174 \cdot 81$ & $130 \cdot 1 \pm 20.62$ & $2 \cdot 2 \pm 0.40$ & $7 \cdot 3 \pm 0.33$ & $3 \cdot 3 \pm 0.15$ & $16 \cdot 2 \pm 1 \cdot 54$ & $28.52 \pm 1.53$ & $46.6 \pm 1.75$ \\
\hline \multicolumn{12}{|c|}{ 'Inactive' chronic hepatocellular disease (group 2) } \\
\hline L.C. & 72 & $\mathbf{F}$ & $\mathbf{A C H}$ & 55 & 40 & 0.8 & $8 \cdot 0$ & $3 \cdot 5$ & 18 & $21 \cdot 0$ & $49 \cdot 5$ \\
\hline S.D. & 24 & $\mathbf{M}$ & ACH & 65 & 35 & 0.9 & $8 \cdot 1$ & $3 \cdot 7$ & 14 & 22.9 & $47 \cdot 2$ \\
\hline E.H. & 47 & $\mathbf{F}$ & $\mathbf{P B C}^{7}$ & 55 & 425 & 0.9 & $7 \cdot 8$ & $4 \cdot 0$ & 18 & $24 \cdot 4$ & 50.5 \\
\hline I.E. & 53 & $\mathbf{M}$ & HC & 80 & 100 & 0.4 & 6.7 & $4 \cdot 2$ & 17 & $22 \cdot 8$ & 55.9 \\
\hline D.D. & 58 & $\mathbf{M}$ & AC & 45 & 50 & 0.4 & $7 \cdot 0$ & $3 \cdot \overline{7}$ & 26 & $23 \cdot 5$ & $51 \cdot 7$ \\
\hline J.W. & 44 & $\mathbf{M}$ & $\mathbf{A C}$ & 75 & 120 & 0.8 & $8 \cdot 6$ & $4 \cdot 3$ & 13 & $28 \cdot 8$ & 60.5 \\
\hline R.W. & 47 & $\mathbf{M}$ & $\mathbf{A C}$ & 245 & 675 & 0.6 & $7 \cdot 5$ & 3.9 & 8 & $30 \cdot 5$ & $52 \cdot 1$ \\
\hline \multicolumn{4}{|c|}{ Mean values $\pm 1 \mathrm{SE}$} & $88 \cdot 6 \pm 24 \cdot 52$ & $206.4 \pm 86.65$ & $0.7 \pm 0.08$ & $7.7 \pm 0.23$ & $3 \cdot 9 \pm 0.10$ & $16.3 \pm 1.95$ & $24 \cdot 84 \pm 1 \cdot 22$ & $54.29 \pm 1.55$ \\
\hline \multicolumn{12}{|c|}{ Acute hepatitis (group 3) } \\
\hline R.S. & 61 & $\mathbf{M}$ & Hepatitis B & 800 & 310 & $12 \cdot 3$ & 6.7 & $3 \cdot 1$ & 16 & 34.0 & $44 \cdot 0$ \\
\hline W.M. & 45 & $\mathbf{F}$ & Hepatitis A & 1850 & 180 & $15 \cdot 7$ & 6.4 & 3.0 & 8 & $32 \cdot 8$ & $41 \cdot 7$ \\
\hline R.H. & 25 & $\mathbf{M}$ & Hepatitis A & 600 & 200 & $2 \cdot 7$ & $7 \cdot 5$ & $3 \cdot 8$ & 15 & $23 \cdot 2$ & $46 \cdot 8$ \\
\hline G.T. & 28 & $\mathbf{M}$ & Hepatitis A & 420 & 100 & $1 \cdot 0$ & $7 \cdot 4$ & $3 \cdot 4$ & 10 & 25.0 & 52.7 \\
\hline G.N. & 30 & $\mathbf{M}$ & Hepatitis A & 255 & 110 & 2.9 & 6.9 & 3.8 & 12 & $28 \cdot 2$ & 55.0 \\
\hline W.S. & 28 & $\mathbf{M}$ & Hepatitis A & 155 & 125 & $2 \cdot 6$ & $7 \cdot 3$ & $4 \cdot 3$ & 21 & $23 \cdot 7$ & 61.9 \\
\hline \multicolumn{4}{|c|}{ Mean values $\pm 1 \mathrm{SE}$} & $680 \pm 230.6$ & $170.8 \pm 29.41$ & $6 \cdot 2 \pm 2 \cdot 30$ & $7 \cdot 0 \pm 0.16$ & $3.6 \pm 0.18$ & $13.7 \pm 1.74$ & $27.8 \pm 1.74$ & $50.35 \pm 2.84$ \\
\hline
\end{tabular}

Table I Clinical and laboratory data of subjects studied

${ }^{1}$ Serum glutamic oxaloacetic transaminase (normal up to $40 \mathrm{Karmen}$ Units $/ 100 \mathrm{ml}$ )

'Serum alkaline phosphatase (normal $80 \mathrm{IU}$ )

Blood urea nitrogen (normal $20 \mathrm{mg} / 100 \mathrm{ml}$ )

Active chronic hepatitis
'Idiopathic haemochromatosis

Alcoholic cirrhosis

'Primary biliary cirrhosis indicated conditions, viz, neurological disease and bronchial asthma. Twenty-two patients with liver disease were studied. Sixteen were suffering from chronic hepatocellular disease (Table I); in nine of the 16 the disease was 'active' at the time of study as judged by elevated serum levels of bilirubin and transaminase (group 1); in the other seven patients the disease was 'inactive' (group 2). The remaining six patients were suffering from acute viral hepatitis of varying severity (group 3 ). In all patients the diagnosis was confirmed by hepatic biopsy.

The plasma prednisolone levels were measured by a modification of the competitive protein-binding method of Murphy (1968). Since cortisol is also measured by this method in addition to prednisolone, the subjects were all given $\mathbf{2} \mathrm{mg}$ dexamethazone orally between $11 \mathrm{p} . \mathrm{m}$. and midnight on the evening before each test to suppress endogenous cortisol production. Dexamethazone is not detected by the assay. Tests for specificity using prednisone and prednisolone standards demonstrated that the extent of detection of prednisone was approximately $10 \%$; for example, $50 \mathrm{ng}$ prednisone produced readings equivalent to $4.3 \mathrm{ng}$ prednisolone and $25 \mathrm{ng}$ prednisone was equivalent to $2 \cdot 8 \mathrm{ng}$ prednisolone.

CONVERSION OF PREDNISONE TO PREDNISOLONE All subjects were studied after the administration of prednisone and prednisolone on separate occasions, each in a single oral dose of $20 \mathrm{mg}$ in the fasting state between 8.30 and $9.30 \mathrm{am}$, and the order of administration of the two drugs was randomized. Both drugs were given as the free alcohol (Panafcort and Panafcortelone, Protea). Venous blood samples were taken at one, two, three, and six hours after administration, and the heparinized plasma was stored at $-20^{\circ} \mathrm{C}$ until tested, usually within one week. Samples stored at $-20^{\circ} \mathrm{C}$ for 12 months showed no fall in prednisolone activity. In some subjects the plasma disappearance $\left(\mathrm{T} \frac{1}{2}\right)$ of pred- 
nisolone was measured after intravenous administration. The prednisolone used in these studies was in the disodium phosphate form.

\section{PLASMA BINDING OF PREDNISOLONE}

The percentage of protein-bound prednisolone in the patients' plasma one hour after drug administration was measured by equilibrium dialysis (McMenamy, 1968). Four $\mathrm{ml}$ heparinized plasma was pipetted into a large test tube containing prednisolone- ${ }^{3} \mathrm{H}^{1}$ (approximately $140 \mathrm{ng}$ containing approximately $800000 \mathrm{cpm}$ in $0.1 \mathrm{ml}$ ethanol). Four $\mathrm{ml}$ of Kreb's phosphate buffer $p \mathrm{H} \mathrm{7.4}$ was then pipetted into a cellophane bag which was placed into the test tube. The test tube was rotated for 15 hours at room temperature $\left(20^{\circ} \mathrm{C}\right)$ to allow equilibration of the steroid between plasma and buffer. The radioactivity in aliquots of buffer and plasma was then measured using Bray's scintillant (Bray, 1960) and a Nuclear Chicago mark II liquid scintillation counter. The cellophane did not bind prednisolone since all the radioactivity added was recovered from the plasma and buffer after 15 hours. This method was also used to study the degree of binding of prednisolone by pooled normal human plasma and the effect in vitro of adding azathioprine.

\section{Results}

CONVERSION OF PREDNISONE TO PREDNISOLONE Figure 1 shows the levels of plasma prednisolone reached after the aministration of $20 \mathrm{mg}$ prednisone or $20 \mathrm{mg}$ prednisolone in control subjects and patients with chronic liver disease. In both the controls and patients with inactive chronic disease (group 2) similar levels of plasma prednisolone were obtained after either drug was administered. In contrast, in patients whose disease was active at the time of study as judged by elevated serum levels of bilirubin and transaminase, significantly higher levels of plasma prednisolone were obtained after prednisolone administration than after prednisone (Figs. 1 and 2). In addition, the peak prednisolone levels (usually at one hour) were significantly higher in the patients with acute or active disease (groups 1 and 3) compared with those patients with inactive disease (group 2) and control subjects (Table I) $(t=2.46 ; P=0.01)$. Plasma levels of prednisolone one hour after prednisone administration were lower in patients than controls (for groups 1,2 , and 3 versus controls $t=2.04 ; P<0.05)$ and the peak levels often occurred later than after prednisolone (Figs. 1 and 2).

${ }^{1}$ Specific activity $2.5 \mathrm{Ci} / \mathrm{m} \mathrm{mol}$, obtained from Radiochemical Centre, Amersham, England.

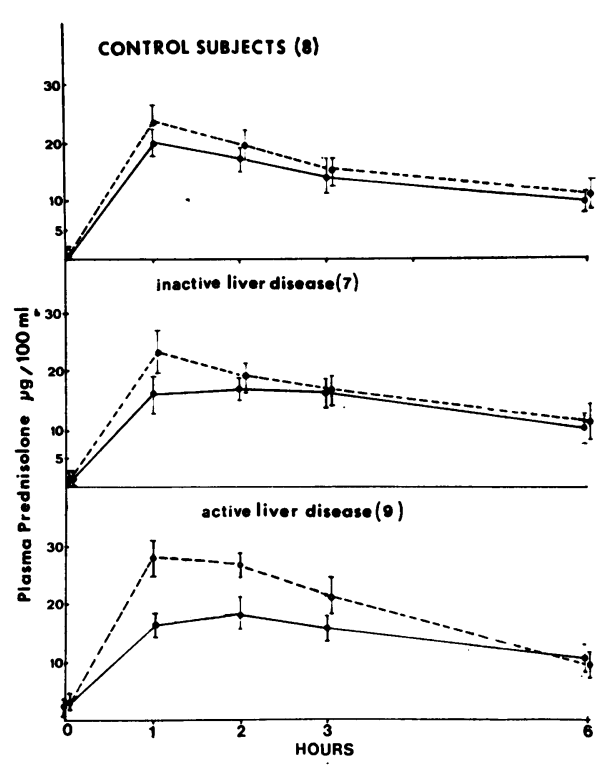

Fig. 1 Plasma prednisolone levels (mean values \pm 1 $S E)$ after the oral administration of $20 \mathrm{mg}$ prednisolone $(\mathrm{O}-.-\mathrm{O})$ and after $20 \mathrm{mg}$ prednisone (O-O) in eight control subjects and 16 patients with chronic liver disease. In the group with active chronic liver disease the levels are significantly higher after prednisolone than after prednisone at one and two hours $(t=3.6$ and 2.6; $\mathrm{P}<0.01$ and $<0.05$ respectively).

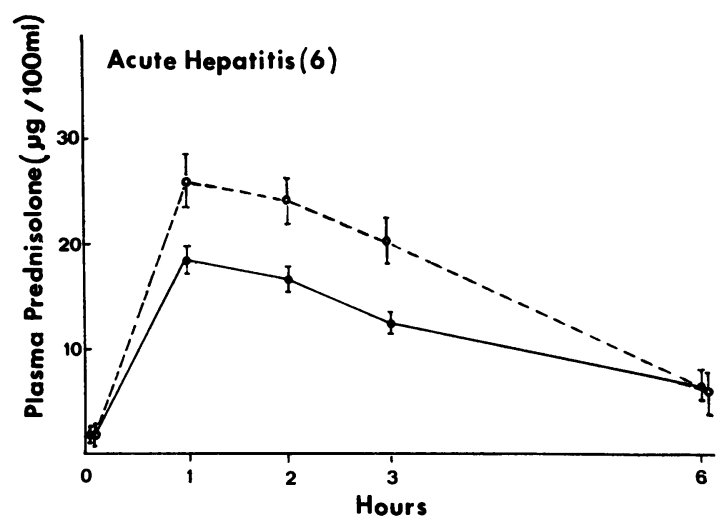

Fig. 2 Plasma prednisolone levels (mean values \pm 1 $S E)$ after the oral administration of $20 \mathrm{mg}$ prednisolone (O - . O) and $20 \mathrm{mg}$ prednisone (O-O) in six patients suffering from acute viral hepatitis. The levels after prednisolone are significantly higher at one, two, and three hours $(t=2.57,2.95$, and $2.25 ; \mathrm{P}<0.05,<0.05$, and $<0.05$ respectively). 
PLASMA PROTEIN BINDING OF PREDNISOLONE Under the in vitro experimental conditions used $53.5 \%$ of the prednisolone in the plasma of control subjects one hour after administration was protein bound (Table I). Similar results were obtained in patients with acute hepatitis and those with 'inactive' chronic disease. In contrast, patients with 'active' chronic hepatocellular disease had significantly less prednisolone bound to plasma proteins $(t=2.48$; $P<0.05$ ). For all patients there was a significant correlation between the extent of plasma binding of prednisolone and the serum albumin concentration (Fig. 3).

There was no significant difference in the level of prednisolone obtained in those patients who had been taking other drugs (diuretics and hypnotics) up to the time of the study compared with those without previous drug therapy. Azathioprine did not affect the binding of prednisolone by plasma proteins in vitro when added in concentrations up to $2 \mathrm{uM}$ (Fig. 4).

PLASMA DISAPPEARANCE OF PREDNISOLONE The plasma disappearance of prednisolone after intravenous injection ( $20 \mathrm{mg}$ ) was measured in three normal control subjects and three patients with chronic liver disease (two with inactive disease and one active). The values for $T_{\frac{1}{2}}$ were 150,180 , and 195 minutes for controls and 195, 220, and 250 minutes for patients respectively.

One patient was studied on three occasions over a 12-month period to detect any alteration in prednisolone metabolism and plasma binding of prednisolone during the course of the disease (Fig. 5). This 33-year-old housewife developed acute hepatitis in December 1970 six months after receiving a blood transfusion during hysterectomy. On admission she was jaundiced and there was evidence of hepatic precoma. Laboratory investigations were consistent with acute hepatocellular disease, and repeated tests for Australia antigenaemia using immunoelectroosmophoresis and complement fixation were negative. Her condition improved with supportive measures and prednisolone therapy but relapse occurred in March 1971, when percutaneous biopsy showed evidence of subacute hepatic necrosis (Boyer and Klatskin, 1971). The first study was performed during this admission (Fig. 5). Higher levels of plasma prednisolone were obtained after administration of prednisolone than after prednisone and the peak plasma level occurred later with prednisone. She was subsequently treated with prednisolone $40 \mathrm{mg} /$ day reducing to a maintenance dose of $15 \mathrm{mg} /$ day and after two months the serum levels of bilirubin, albumin, and transaminase had returned to normal. However, repeat liver biopsy in

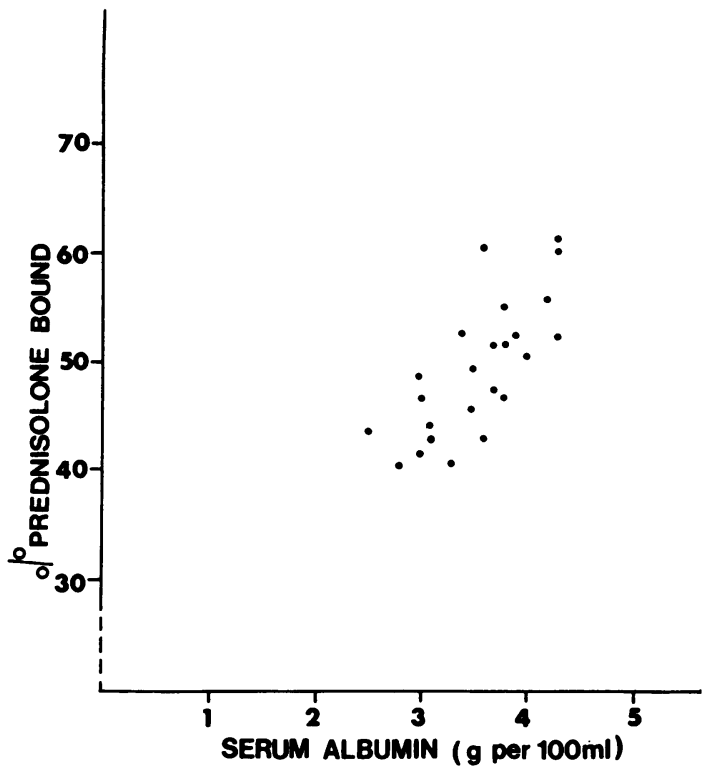

Fig. 3 Relationship between plasma prednisolone level and serum albumin concentration in patients with liver disease (Table I) $(r=0.75 ; \mathrm{P}<0.001)$.

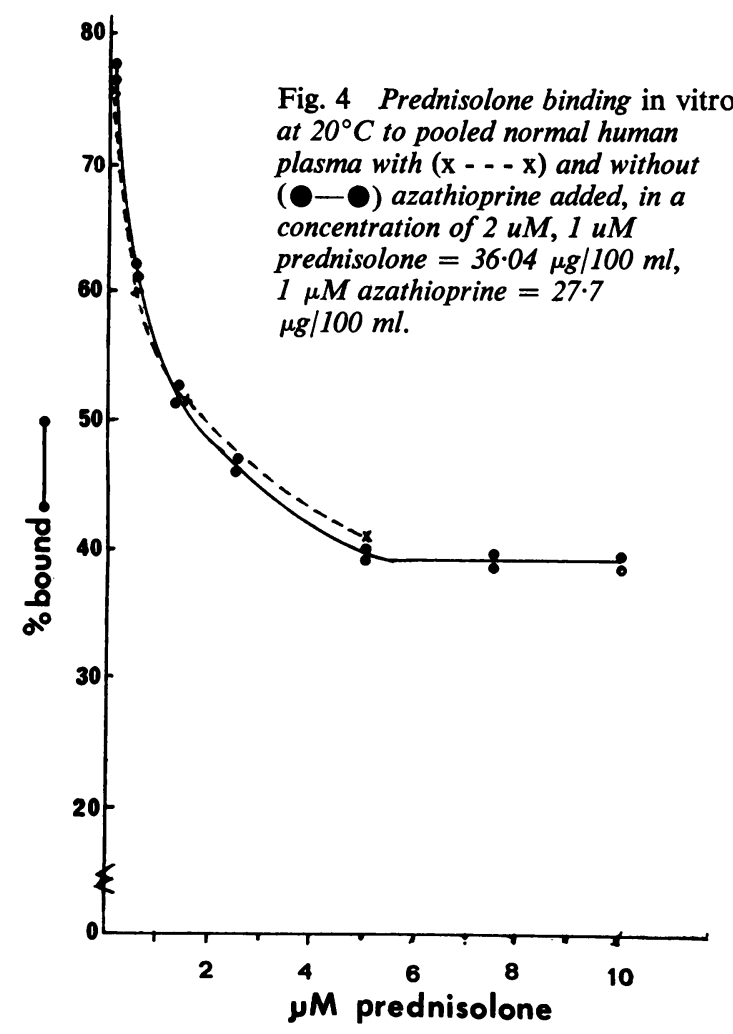




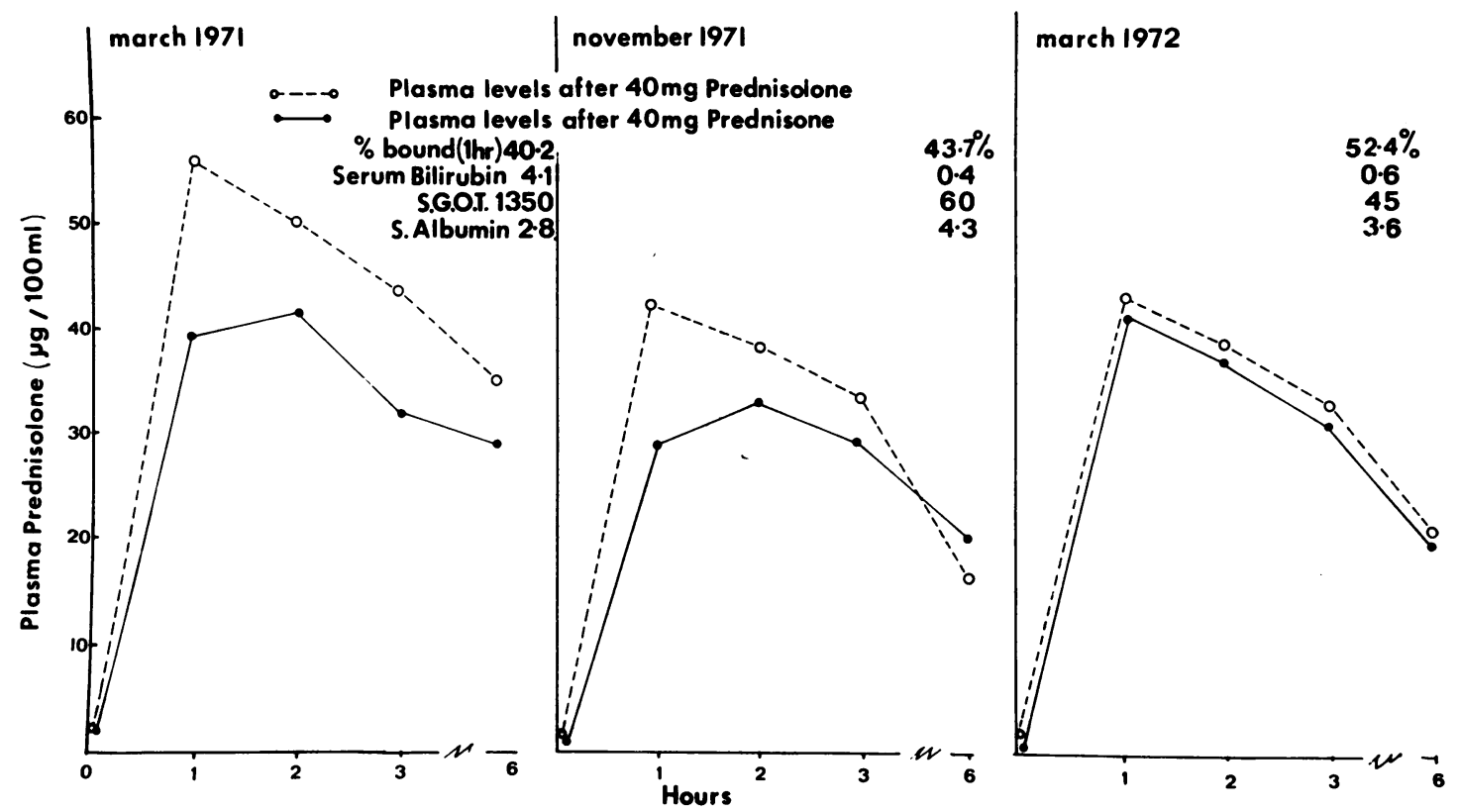

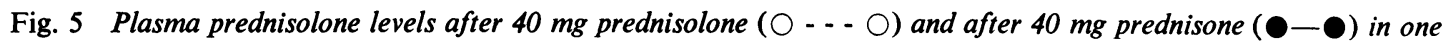
patient (B.T.) on three separate occasions (see Table I and text).

November 1971 showed the presence of an active 'aggressive' perilobular hepatitis with cirrhosis. The prednisolone studies were repeated at this time and again higher levels of serum prednisolone were obtained after administration of prednisolone than after prednisone (Fig. 5). However, the levels reached in the plasma and amount of unbound steroid were lower than in the first study. When reassessed in March 1972 the patient was still asymptomatic, serum biochemical values were normal, and a further percutaneous liver biopsy revealed cirrhosis with considerably less inflammatory infiltrate. On this occasion the pattern of serum prednisolone levels after administration was similar to that in normal subjects (Fig. 5).

\section{Discussion}

The pharmacological basis of corticosteroid therapy in liver disease presumably depends on achievement of an adequate plasma level of unbound drug which is the biologically active moiety: in the case of prednisone its conversion to prednisolone in the liver is necessary in addition before biological activity. However, little attention has been given to the metabolism and plasma protein binding of prednisone and prednisolone in patients with liver disease. This is surprising in view of the fact that the metabolic fate of cortisol analogues may be considerably different from that of cortisol itself (Sandberg and Slaunwhite, 1957; Cope, 1964). Jenkins and Sampson (1967) reported that, although lower plasma levels of cortisol were obtained after the administration of cortisone than after cortisol, prednisone appeared to be converted to prednisolone with a high degree of efficiency. However, these authors studied only two patients with liver disease, one with hepatitis and one with cirrhosis, and no details of severity of the illnesses were given. Similarly, Peterson (1960) studied the metabolism of prednisolone in only one patient with cirrhosis (and he found it slower than normal) and Bunim, Pechet, and Bollet (1955) did not include patients with severe hepatic disease in their series.

In the present study significantly higher plasma levels of prednisolone were obtained after oral administration of prednisolone than after prednisone in patients with acute or active liver disease. It seems likely that this was due both to impairment of the hepatic enzyme $11 \beta$-hydroxydehydrogenase, which renders the 11-oxosteroids cortisone and prednisone biologically active, and also impairment of ring A reduction of prednisolone, for the following reasons: 
(a) The plasma prednisolone levels one hour after oral prednisone administration were lower in patients with liver disease than in control subjects (Table I).

(b) The peak plasma prednisolone tended to occur later, ie, at two hours, in patients with liver disease after oral prednisone compared with plasma levels after oral prednisolone.

(c) The intestinal absorption of prednisone does not differ markedly from prednisolone (Shedl and Clifton, 1961).

(d) The $\mathrm{T}_{\frac{1}{2}}$ for prednisolone was prolonged in two of three patients with liver disease studied, as was found in one patient by Peterson (1959).

Probably of even greater practical importance is the finding that higher plasma levels of unbound (and therefore biologically active) steroid were obtained in patients with acute disease. Several factors probably contributed to this difference. First, there were significantly higher total levels of prednisolone in patients with active disease (Table I) and this would therefore lead to a higher percentage of circulating unbound drug (see Fig. 4). Secondly, there was a significant positive correlation between the proportion of bound prednisolone and serum albumin levels; therefore with lower serum albumin concentrations there is more unbound corticosteroid in plasma. Lewis, Jusko, Burke, and Graves (1971) showed that there was a correlation between the frequency of side effects from corticosteroids, the mean daily prednisone dose, and the serum albumin levels in a group of patients treated with corticosteroids for various diseases. When the serum albumin concentration was less than $2.5 \mathrm{~g} / 100 \mathrm{ml}$ the frequency of side effects was doubled. They concluded that the low protein binding of prednisolone due to hypoalbuminaemia was a major contributing factor to the increased incidence of side effects in these subjects, although they suggested that, in addition, the low albumin levels may be a marker for impaired liver cell function and therefore altered steroid inactivation. Our findings support this conclusion since the serum albumin concentrations and degree of plasma protein binding were lower in patients with active and acute disease than in the 'inactive' group. A further factor which may have contributed to the higher plasma levels of unbound steroid was the effect of the hepatic disease on corticosteroid-binding globulin, the synthesis of which also occurs in the liver and may be impaired in hepatic disease.

Our data provide support for the empirical findings of Cook et al (1971) that low-dose corticosteroid therapy is effective in active chronic hepatitis and is associated with a low complication rate. Patients with acute or active disease have more unbound drug in the plasma, especially if the serum albumin concentration is low. However, these authors recommended that steroid doses be adjusted on the basis of the serum albumin and globulin levels, larger doses being given when the serum albumin was low since this is a reflection of more severe hepatocellular disease. From the present studies it would seem that this practice is likely to lead to a substantial increase in the level of circulating unbound prednisolone with a substantial increase in side effects. It is suggested, therefore, that when treating patients with severe or active disease, prednisolone should be used routinely and that the dose administered should be adjusted by small increments such as 1 to $2 \mathrm{mg}$ per day until satisfactory control is achieved with minimum toxic effects.

Since azathioprine appears to have a significant beneficial effect in patients with active chronic hepatitis when used with corticosteroids (Mackay, 1968), but less so when used alone (Sherlock, 1971), we thought it possible that the two drugs might interact. The present study has shown that azathioprine has no effect in vitro on the binding of prednisolone by normal human plasma, and it seems unlikely therefore that the reported beneficial effect of this drug in liver disease is due to any resultant alteration in the level of unbound circulating corticosteroid. However, this does not exclude the possibility that azathioprine affects the hepatic metabolism of prednisolone and other corticosteroids.

Alternate-day corticosteroid régimes have been shown to produce beneficial results with fewer toxic effects in patients with non-hepatic diseases such as bronchial asthma and myasthenia gravis (Warmolts and Engel, 1972). From our findings we deduce that these régimes would result in very high levels of unbound steroids for short periods. Such studies would be of interest in patients with hepatic disease since toxic effects are relatively common in this group. It is still uncertain whether, in treating patients with liver disease with corticosteroids, it is preferable to maintain a constant plasma level of unbound steroid or to produce very high levels intermittently.

We wish to express our thanks to those physicians at the Royal Brisbane Hospital who allowed us to study patients under their care, and to $\mathrm{Mr} \mathbf{B}$. Nurnberg, Department of Pathology, Royal Brisbane Hospital, for invaluable assistance with the steroid assays.

\section{References}

Boyer, J. L., and Klatskin, G. (1970). Pattern of necrosis in acute viral hepatitis: prognostic value of bridging (subacute hepatic necrosis). New Engl J. Med., 283, 1063-1071. 
696

L. W. Powell and Elizabeth Axelsen

Bray, G. A. (1960). A simple efficient liquid scintillator for counting aqueous solutions in a liquid scintillation counter. Analyst. Biochem., 1, 279-285.

Bunin, J. J., Pechet, M. M., and Bollet, A. J. (1955). Studies on metacortandralone and metacortandracin in rheumatoid arthritis: antirheumatic potency, metabolic effects, and hormonal properties. J. amer. med. Ass., 157, 311-318.

Cook, G. C., Mulligan, R., and Sherlock, S. (1971). Controlled prospective trial of corticosteroid therapy in active chronic hepatitis. Quart. J. Med., 158, 159-185.

Cope, C. L. (1964), Adrenal Steroids and Disease, p. 88. Pitmans, London,

Copenhagen Study Group for Liver Disease (1969). Effect of prednisone on the survival of patients with cirrhosis of the liver: a report. Lancet, 1, 119-121.

Jenkins, J. S., and Sampson, P. A. (1967). Conversion of cortisone to cortisol and prednisone to prednisolone. Brit. med. J., 2, 205207.

Lewis, G. P., Jusko, W. J., Burke, C. W., and Graves, L. (1971). Prednisone side-effects and serum-protein levels. A collatorative study. Lancet, $2,778-781$.
Mackay, I. R. (1968). Chronic hepatitis: effect of prolonged suppressive treatment and comparison of azathioprine with prednisolone. Quart. J. Med., 37, 379-392.

McMenamy, R. H. (1968). Binding studies by dialysis equilibrium: a description of an accurate and rapid technique. Analyst. Biochem., 23, 122-128.

Murphy, B. E. P. (1968). Clinical evaluation of urinary cortisol determinations by competitive protein-binding radioassay. $\mathrm{J}$. cline. Endocr., 28, 343-348.

Peterson, R. E. (1960). Adrenocortical steroid metabolism and adrenal cortical function in liver disease. J. chin. Invest., 39, 320-331.

Sandberg, A. A., and Slaunwhite, W. R., Jr. (1957). Differences in metabolism of prednisolone-C ${ }^{14}$ and cortisol-C ${ }^{14}$. J. chin. Endoc., 17, 1040-1050.

Schedl, H. P., and Clifton, J. A. (1961). Small intestinal absorption of steroids. Gastroenterology, 41, 491-499.

Sherlock, S. (1971). Active chronic hepatitis: Definition diagnosis and management. Postgrad. med., 50, 206-211. (Nov.)

Warmolts, J. R., and Engel, W. K. (1972). Benefit from alternate-day prednisone in myasthenia graves. New Angl. J. Med., 286, 17-20.

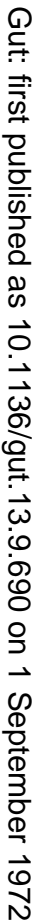

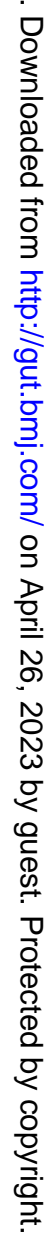

